Original Research Paper

\title{
Human Adipose Stem Cells in Collagen on Angiogenesis Process of Burn Healing in Rat Model: Its Number of Blood Vessels
}

\author{
${ }^{1}$ Luluk Yunaini, ${ }^{1}$ Puji Sari, ${ }^{2}$ Dwi Pratami Septiara, ${ }^{2}$ Helsy Junaidi and ${ }^{3}$ Radiana D Antarianto \\ ${ }^{1}$ Department of Medical Biology, Faculty of Medicine, Universitas Indonesia, Jakarta 10430, Indonesia \\ ${ }^{2}$ Master Program in Biomedical Science, Faculty of Medicine, Universitas Indonesia, Jakarta 10430, Indonesia \\ ${ }^{3}$ Department of Histology, Faculty of Medicine, Universitas Indonesia, Jakarta 10430, Indonesia
}

\author{
Article history \\ Received: 28-11-2018 \\ Revised: 24-12-2018 \\ Accepted: 5-01-2019 \\ Corresponding Author: \\ Luluk Yunaini \\ Department of Medical \\ Biology, Faculty of Medicine, \\ Universitas Indonesia, Jl. \\ Salemba Raya No.6, Jakarta \\ 10430, Indonesia \\ Tel: +62-21-31930379 \\ Fax: +62-21-31907281 \\ Email: luluk.yunaini@ui.ac.id
}

\begin{abstract}
Angiogenesis in the burn wound healing process is important. The application stem cell therapy in burn wound problem is expected to increase formation of new blood vessel so that the distribution of oxygen and nutrients working well. The purpose of this study was to known effect of human Adipose Derived Stem Cell (hADSC) in collagen gel on the average number of blood vessels based on time dependent. This study used 25 male rats Sprague Dawley who had received three internal wounds with different treatments. The treatments used hADSC in collagen gel, collagen gel only and without treatment. The rats were divided into 5 groups based on the duration of observation day $0,7,14,21$ and 28. Rat without burn wound were used as control. Observation blood vessels number using hematoxylin-eosin staining and calculated of average number blood vessels from five filed in five mice. Statistical analysis used ANOVA one way with significance value $\mathrm{p}<0.05$. The average number blood vessels increase significantly until day 21 and decreased on day 28 , both in untreated burn wound, collagen gel and hADSC in collagen gel. The treatment with hADSC in collagen gel was not significantly different from the collagen gel group or without treatment at day 7,14 and 21. Even though the average of blood vessels of treatment with hADSC in collagen gel was not significantly different but our research had showed that treatment with hADSC in collagen gel was higher number of blood vessels than another group. Decrease of blood vessel number at 28 days indicated start of near homeostasis state and treatment hADSC in collagen gel has significantly decreased than another group. Our research showed that angiogenesis was time dependent and hADSC in collagen gel have not a role in increase of number blood vessels but we have indicated that hADSC might be have a role in qualitative improvement of angiogenesis.
\end{abstract}

Keywords: hADSC, Collagen Gel, Blood Vessels, Burn Healing, Rat Model

\section{Introduction}

This Burn wound are global health problem because they are one of the main causes of morbidity and mortality (Yang, 2015). Burn wound can be classified based on the depth of skin tissue damage, namely superficial burn wound, superficial dermal burn wound, deep dermal burn wound and full thickness burn wound (Moenadjat, 2009). Based on the severity of tissue damage and changes in blood flow, the burn wound area can be classified into a coagulation zone, stasis zone and hyperemia zone (Rowan et al., 2015; Moenadjat, 2016).
The re-establishment of new blood vessels (angiogenesis) in the healing process of burn wound is indispensable because blood vessels carry oxygen and nutrients to damaged or infected tissues, carry immune cells and prepare wound areas for tissue regeneration and repair (Morton and Phillips, 2012; Lee et al., 2016). Therefore, the vascular system plays an important role in maintaining and restoring local homeostasis conditions (Busuioc et al., 2011). Growth factors that play an important role in the process of blood vessel formation are Fibroblast Growth Factor (FGF), Vascular Endothelial Growth Factor (VEGF) 
and angiopoietin-1 (ang-1) (Bates and Jones, 2003; Dulak et al., 2013; Johnson and Wilgus, 2014).

Studies on the use of mesenchymal stem cells in tissue regeneration have been reported (Cejka, 2016; Pawitan et al., 2017). Advantage of mesenchymal stem cells is multi-potent cells, easily obtained and has low immunogenicity (Estrada, 2009; Wei et al., 2013). The three most widely used sources for obtaining mesenchymal stem cells are bone marrow, cord blood and fat tissue. A study by Sari et al. (2018) showed an increase in VEGF mRNA expression in burn wound that had been given human adipose-derived stem cell (hADSC) in collagen gel.

In the present study, we investigate the role of hADSC in the process of angiogenesis with the parameters used in the average amount of blood vessel.

\section{Material and Methods}

\section{Research Design}

This research was a randomized controlled parallel experimental study with experimental animals in the form of male Sprague Dawley rats. This research was conducted with permission from the health research ethics committee FKUI-RSCM with a number 17-03-0261.

\section{Human Adipose-derived Stem Cell}

Human adipose tissue as a source of mesenchymal stem cells was taken from the liposuction at "erpour beauty clinic". Adipose tissue isolated to obtain the human adipose derived stem cell (hADSC). Then, culture and characterization of mesenchymal stem cells were carried out.

Human adipose-derived stem cells (hADSC) were obtained according to the method of Pawitan et al. (2013) who used coffee filters. Adipose tissue was filtered with a tea filter and washed with PBS (3-4 times washing). After cleaning, the sample was digested with collagenase type 1 for 1 hour in $\mathrm{CO}_{2}$ incubator at $37^{\circ} \mathrm{C}$ with $5 \%$ of $\mathrm{CO}_{2}$. The top layer was removed from the low layer (containing cell emulsion). Nylon $100 \mu \mathrm{m}$ filter was used to filter cell emulsion and then centrifuge at $1.200 \mathrm{rpm}$ for $10 \mathrm{~min}$. The pellet was added of $10 \mathrm{~mL}$ lysis buffer with $100 \mu \mathrm{L}$ of fungicide and $100 \mu \mathrm{L}$ of the Penicillin/Streptomycin and then incubated at room temperature for $15 \mathrm{~min}$. The mixture was centrifuged at 1,200 rpm for $10 \mathrm{~min}$. The pellet was added 1-2 $\mathrm{ml}$ of DMEM containing 10\% PRP, (Lunstrum and Horton, 1999; Guo et al., 2014) 1\% Penicillin/Streptomycin, 1\% heparin and $1 \%$ fungicide. Then homogenize and grow in 6 well plates with $1.5-2 \mathrm{~mL}$ media/well. Cell culture was grown in an incubator at $37^{\circ} \mathrm{C}$ with $5 \%$ of $\mathrm{CO}_{2}$. The medium is replaced every 2-3 days and harvested after $80 \%$ confluent cells. Mesenchymal stem cells that have been isolated and cultured were characterized by flow cytometry and cell differentiation into chondrocyte, osteocyte and adipose cells (Fig.1).

\section{Animal Model of Deep Burn Wound}

In this study, 25 Sprague Dawley strain male rat with 10 week old were used. The burn wound on the animals was made following the method described in Sari et al. (2018) each animal were given three burns with a diameter of $10 \mathrm{~mm}$ (Fig. 2). These experimental animals were divided into 5 groups based on the duration of the trial, which were $0,7,14,21$ and 28 days.

\section{Stem Cell Transplant}

Transplantation uses hADSC as much as $1 \times 10^{6}$ cells in the collagen gel in the right wound. The left wound was given a solution of collagen gel and the lower part of the wound without any treatment. The wound was then closed with tegaderm.

\section{Preparation of Experimental Animal Tissue}

Tissue was fixed by formalin. After that, tissue is dehydrated through a series of graded ethanol baths from low to high concentration and followed by the final dehydration using xylol. After water on tissue displace and then infiltrated with paraffin wax. The infiltrated tissues were embedded into paraffin wax blocks. Sectioning paraffin tissue blocks using microtome with a thickness of 5 $\mu \mathrm{m}$. Staining of preparations using Hematoxylin-Eosin.
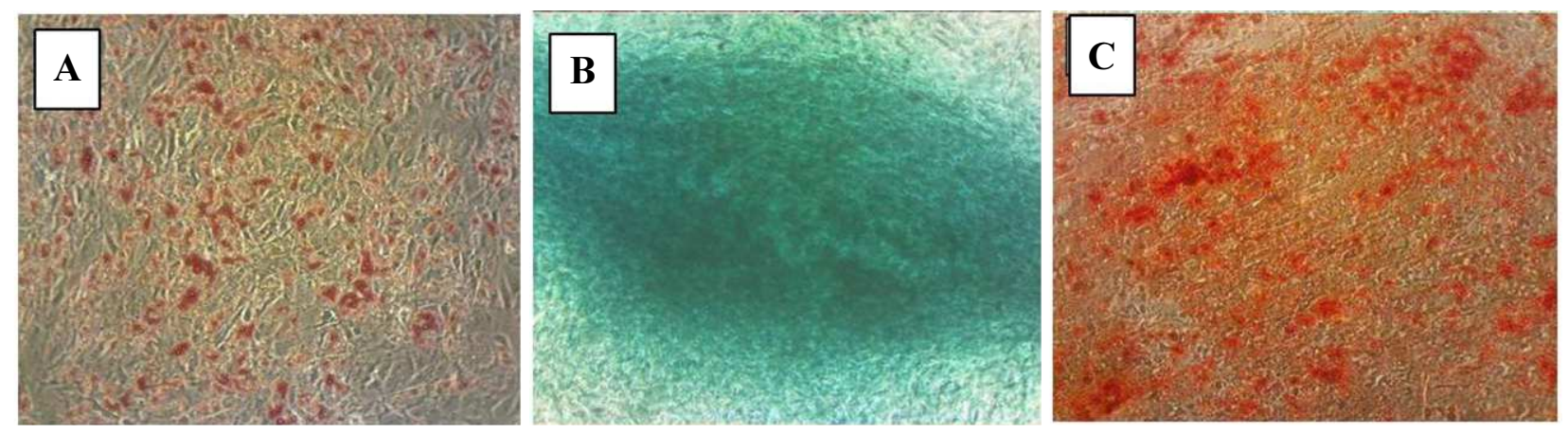

Fig. 1: Differentiation cells from hADSC. The hADSC differentiation becomes adipogenic with oil red staining (A) condrogenic with alcian blue staining (B) and osteogenic with alizarin red staining (C) Magnification 400x 


\section{Calculation of the Amount of Blood Vessels}

Calculation of the amount of blood vessel was done in the dermis area and then taken with a magnification of 400 times as much as 5 fields of view. Optilab camera advances plus was used to documentation histology result. We used Image Raster software to calculation of blood vessels. The results of the 5 field of view were an average. Assessment of the number of blood vessels was carried out by two observers so that their suitability was assessed with the Bland-Altman technique to determine the suitability of the results of reduction (Giavarina, 2015; Juniarti, 2014).

\section{Analysis Statistic}

Statistical analysis was done using SPSS software version 17. The statistical test used ANOVA one-way followed by a post hoc test. The significance value used was $\mathrm{p}<0.05$.

\section{Results}

The results of HE coloring and observation of the number of blood vessels can be seen in Fig. 3. Statistical analysis showed that there were no significant differences between the number of blood vessels in the treatment of addition of hADSC in collagen gel, collagen gel or without treatment, both on days $0,7,14$ and 28 day. The average amount of blood vessels both in the three treatments experienced a significant increase until day 21 and decreased on day 28. Results can be seen in Fig. 4.

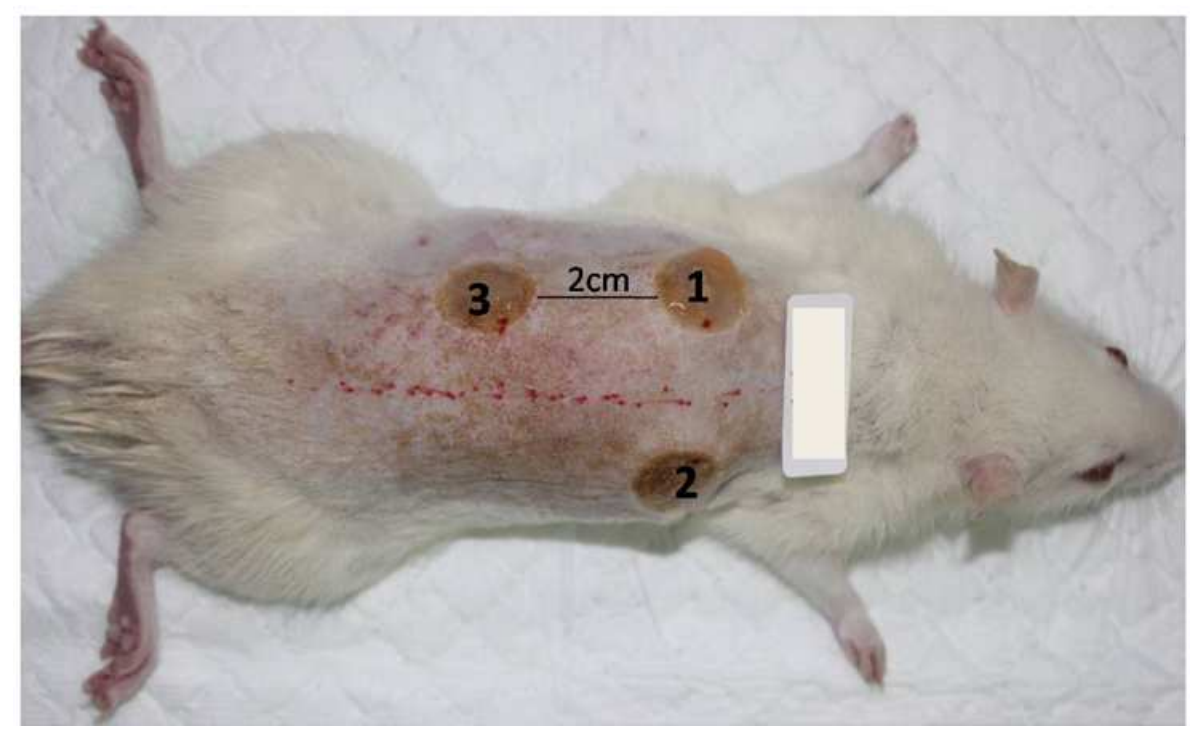

Fig. 2: Animal model with deep burn wound. Each rat has three burn wound in dorsal region. Wounds were made parallel with $1 \mathrm{~cm}$ distance on the right and left sides of vertebral bone; $0.5 \mathrm{~cm}$ below the scapulae and $2 \mathrm{~cm}$ between the vertical wound. Rat skin was injured by attaching $15 \mathrm{sec}$ metal plate to skin used a circular metal plate with $1 \mathrm{~cm}$ diameter which has been heated over Bunsen to a temperature of $250^{\circ} \mathrm{C}$. 1: deep burn wound with collagen gel, 2: deep burn wound with hADSC in collagen gel and 3: deep burn wound without treatment

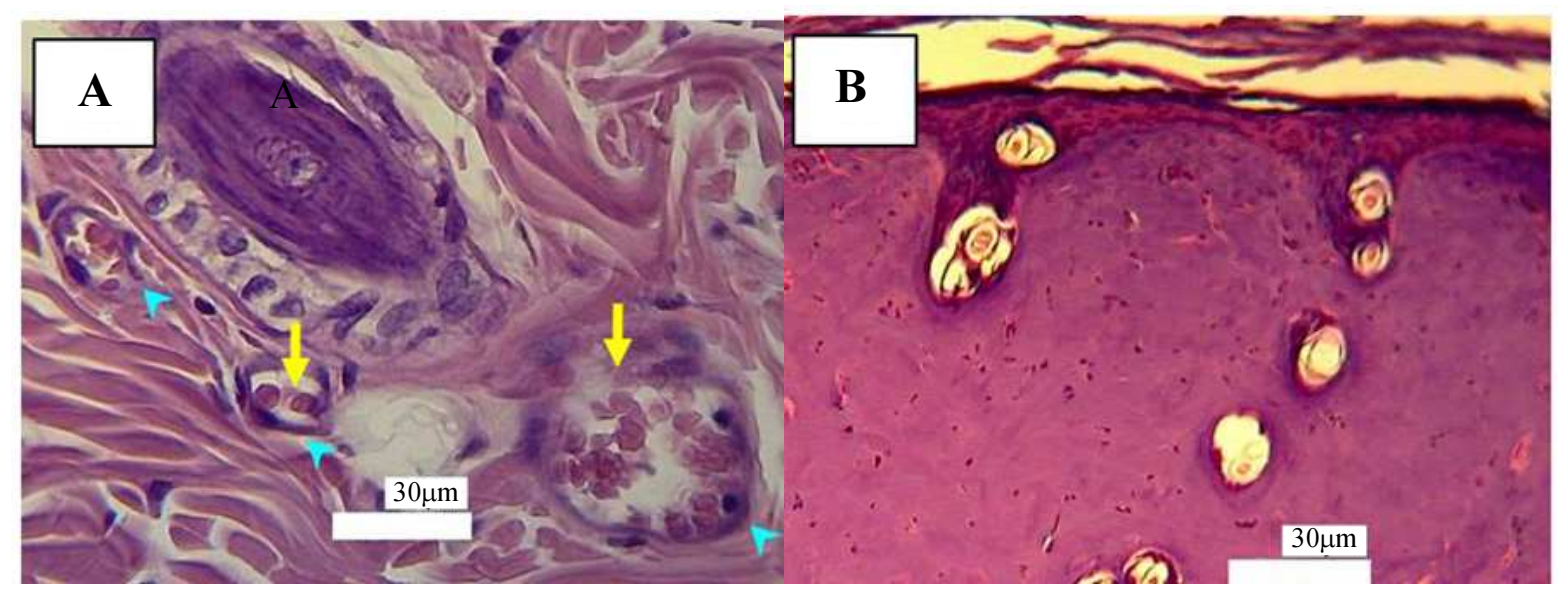




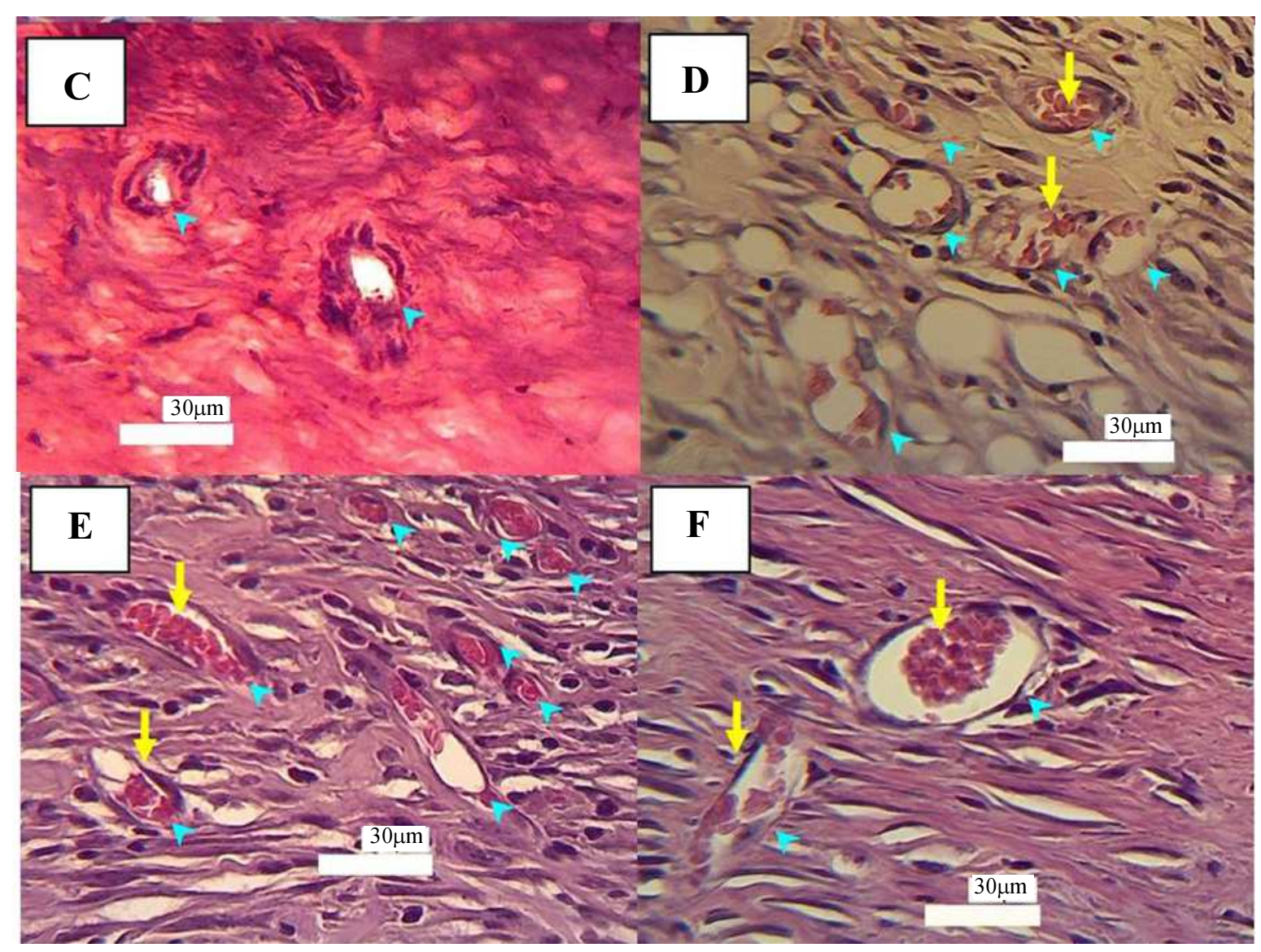

Fig. 3: Histology of rat skin tissue from deep burn wound with HE staining using $400 \mathrm{x}$ magnifications. (A) Normal Skin (B) 0 day after deep burn (C) 7th day after burn (D) 14th day after burn (E) 21 st day after deep burn (F) 28th day after deep burn. Head arrow mean blood vessel and arrow mean blood cells. Our result showed that 0 day after deep burn no blood vessel identified. We found with clear blood cell in blood vessel lumen on 14th, 21st and 28th day

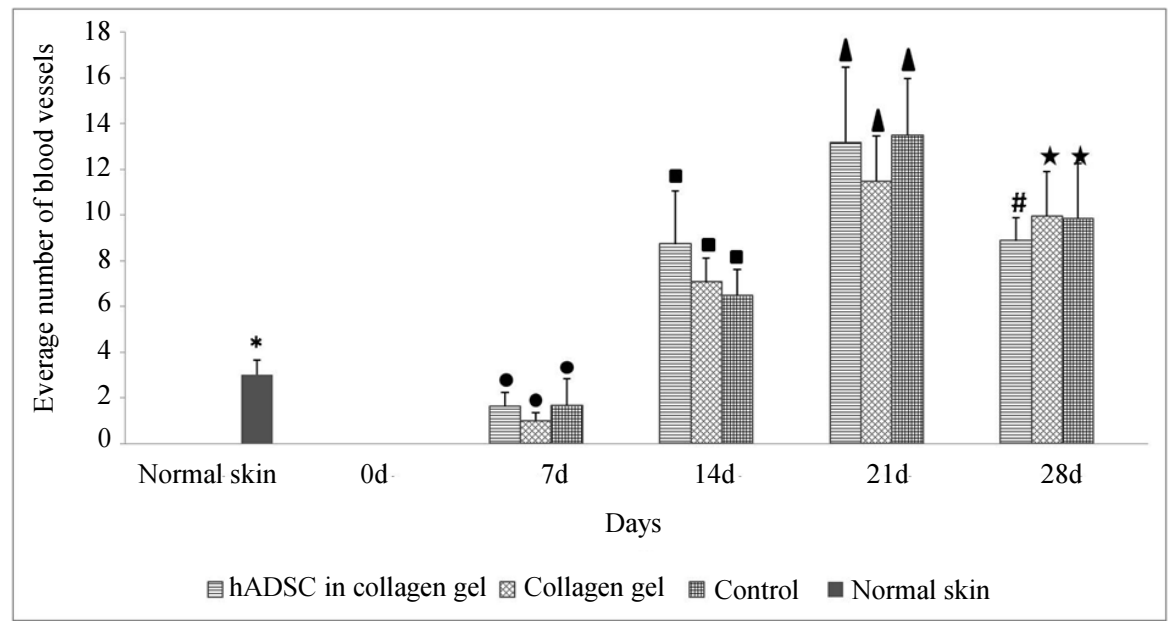

Fig. 4: The average amount of blood vessels in wound tissue. The average of blood vessels has increased significantly since the 14th to 21 st day compared to normal skin conditions. On the 28th day the mean of blood vessels have significant decrease in the burn wound group by giving hADSC in a collagen gel. There was no significant difference between the treatment of hADSC in collagen gel, collagen gel alone or without treatment. Same symbol indicates no statistically significant difference in treatment group (treatment of hADSC in collagen gel, collagen gel and without treatment), while different symbol indicates statistically significant difference in group base on time 


\section{Discussion}

Histology result on the seventh day has showed a small blood vessels and rarely blood cells in the lumen. Identification of blood vessels on seventh day was done by looking at the endothelial in the blood vessels. Blood cells begin to appear clear and numerous on 14 to 28 days. Blood cell enhancement on lumen of blood vessel indicates an increase in oxygen transport to improve hypoxic conditions that occur due to burns. These results had showed an improvement in the quality of blood vessels with increasing time.

This study showed an increase in the average amount of blood vessels until day 21 and decreased on the 28th day for all three treatments. The increase in up to day 21 is likely due to the hypoxic conditions. Exposure to high heat in the tissues caused damage in the blood vessels flow that make a low oxygen level in the burn tissue. This hypoxic condition will induce angiogenesis to make oxygen levels return to normal.

The results of this study were not accordance with Busuioc et al. (2011) which shows that the number of blood vessels began to increase on days 6 to 15 and decreased on day 18 . This was probably due to the different strains of the animal model, Wistar rats with a body weight of 290-340 $\mathrm{g}$ and long healing of deep burn wound.

Sari et al. (2018) reported that VEGF expression increased in the treatment of hADSC in collagen gel on the 7th day and decreased the following day. This is not in line with the results of this study which showed that the number of blood vessels increased until the 14th day. This showed that VEGF-A expression is negatively correlated with the number of blood vessels until the 21st day. On the 28th day both VEGFR expression and the number of blood vessels decreased. VEGF-A is one of the inducers of angiogenesis. In addition to VEGF-A, proteins that play a role in the induction of angiogenesis are FGF and angiopoietin-1 (Dulak et al., 2013). This shows that blood vessel formation is not only influenced by VEGF-A.

VEGF protein will bind to its receptors namely VEGFR1 and VEGFR2 which are present on the surface of the developing vascular endothelial cells as well as maturation. In the angiogenesis process VEGFR2 has a more dominant role because VEGFR1 has the opposite function with VEGFR2 which inhibits angiogenesis (Koch and Claesson-Welsh, 2012). Study conducted by Kumar et al. (2009) which showed an increase in VEGF and VEGFR2 expression and a decrease in VEGFR1 expression in wound tissue.

The results of this study indicate that there was no significant difference between hADSC in collagen gel compared with collagen or untreated gel at day 7, 14 and 21. This showed that hADSC did not have much effect on increasing angiogenesis. Angiogenesis occurs during the proliferation phase which is characterized by fibroblast migration, re-epithelialization, extracellular matrix deposition and angiogenesis, as well as granulation tissue formation and collagen synthesis ( $\mathrm{Li}$ et al., 2007; Enoch and Leaper, 2008; Guo and DiPietro, 2010). Although the number of blood vessels showed no statistically significant differences in the three treatments, hADSC in collagen has a higher tendency for blood vessels to be compared with the other two treatments. This showed that the wound quality in the hADSC group in collagen gel was better than without hADSC.

There was a decrease in the average number of blood vessels on the 28th day compared to the 21 st day for all treatments. The hADSC in collagen gel was significant decrease in the average number of blood vessels than the other treatment groups. In our result showed that the group of mice without burn wounds has a small number of blood vessels. This information indicated that Decrease in the number of blood vessels on day 28 was thought to be caused by burn tissue reaching a state of near homeostasis. A significant decrease in the treatment group with hADSC in collagen gel on the 28th day indicated that the addition of hADSC in collagen gel could improve the quality of healing of burns. When the burn has received enough oxygen, VEGF-A levels return to normal and the blood vessels regress so that the amount decreases (Bao, 2009).

Angiogenesis that occurs in deep dermal burns may originate from vital tissue which is just below the wound. The tissue exposed to the heat has experienced necrosis so it is unable to regenerate. Regeneration can be started from the tissue that is right under the burn and the tissue around the burn.

\section{Conclusion}

The addition of hADSC in collagen gel in deep burn wound did not show a significant role in blood vessel enhancement, but showed an increase in qualitative improvement in deep burn wound healing.

\section{Funding Information}

This research was supported by DRPM UI for providing the PITTA Grant.

\section{Author's Contributions}

All authors contributed equally in this work.

\section{Conflicts of Interest}

There are no conflicts of interest.

\section{Ethics}

This article is original and contains unpublished material. This research has received permission from 
Research Ethics Committee of Faculty of Medicine University Indonesia with No. 17-03-0261.

\section{References}

Bao, P., 2009. The role of vascular endothelial growth factor in wound healing. J. Surgical Res., 153: 347-358. DOI: 10.1016/j.jss.2008.04.023

Bates, D.O. and R.O.P. Jones, 2003. The role of vascular endothelial growth factor in wound healing. Int. J. Lower Extremity Wounds, 2: 107-120. DOI: $10.1177 / 1534734603256626$

Busuioc, C.J., F.C. Popescu and G.D. Mogoşanu, 2011. Angiogenesis assessment in experimental third degree skin burns: A histological and immunohistochemical study. Rom J. Morphol. Embryol., 52: 887-895.

DOI: 10.1109/ STH ERM.2004.1291327

Cejka, C., 2016. The favorable effect of mesenchymal stem cell treatment on the antioxidant protective mechanism in the corneal epithelium and renewal of corneal optical properties changed after alkali burns. Oxid Med Cell Longev. pp: 1-12.

Dulak, J., A. Jozkowicz and A. Loboda, 2013. Angiogenesis and vascularisation: Cellular and molecular mechanisms in health and diseases. DOI: $10.1007 / 978-3-7091-1428-5$

Enoch, S. and D.J. Leaper, 2008. Basic science of wound healing. Surgery, 26: 31-37. DOI: 10.1016/j.mpsur.2007.11.005

Estrada, 2009. Secretome from mesenchymal stem cells induces angiogenesis via Cyr61. J. Cellular Physiology, 219: 563-571. DOI: 10.1002/jcp.21701

Giavarina, D., 2015. Understanding bland altman analysis. Biochemia Medica, 25: 141-151. DOI: 10.11613/BM.2015.015

Guo, P., Z.L. Shi, A. Liu, T. Lin and F. Bi et al., 2014. Effects of cartilage oligomeric matrix protein on bone morphogenetic protein-2-induced differentiation of mesenchymal stem cells. Orthop. Surgery, 6: 280-287. DOI: $10.1111 /$ os. 12135

Guo, S. and L.A. DiPietro, 2010. Factors affecting wound healing. J. Dental Res., 89: 219-229. DOI: $10.1177 / 0022034509359125$

Johnson, K.E. and T.A. Wilgus, 2014. Vascular endothelial growth factor and angiogenesis in the regulation of cutaneous wound repair. Adv. Wound Care, 3: 647-661. DOI: 10.1089/wound.2013.0517

Juniarti, 2014. Pengaruh Pemberian Ekstrak Daun Jarak Tintir (Jatropha multifida L) Secara Topikal Pada Proses Inflamasi dan Fibroplasia Luka Sayat kulit [disertasi]. Jakarta: Universitas Indonesia.
Koch, S. and L. Claesson-Welsh, 2012. Signal transduction by vascular endothelial growth factor receptors. Cold Spring Harbor perspectives in medicine. Cold Spring Harb Perspect. Med., 2: a006502. DOI: 10.1101/cshperspect.a006502

Kumar, I., C.A. Staton, S.S. Cross, M.W. R. Reed and N.J. Brown, 2009. Angiogenesis, vascular endothelial growth factor and its receptors in human surgical wounds. BJS., 96: 1484-1491.

DOI: $10.1002 /$ bjs.6778

Lee, D.E., N. Ayoub and D.K. Agrawal, 2016. Mesenchymal stem cells and cutaneous wound healing: novel methods to increase cell delivery and therapeutic efficacy. Stem Cell Research Therapy, 7: 37. DOI: $10.1186 / \mathrm{s} 13287-016-0303-6$

Li, J., J. Chen and R. Kirsner, 2007. Pathophysiology of acute wound healing. Clinics Dermatology, 25: 9-18. DOI: 10.1016/j.clindermatol.2006.09.007

Lunstrum, G.P. and W.A. Horton, 1999. Chondrocyte differentiation in a rat mesenchymal cell line. J. Histochemistry Cytochemistry. J. Histochemistry Cytochemistry, 47: 1-6. DOI: $10.1177 / 002215549904700101$

Moenadjat, Y., 2009. Luka Bakar: Masalah dan Tatalaksana. Fakultas Kedokteran Universitas Indonesia.

Moenadjat, Y., 2016. Luka Bakar Pediatrik. Sagung Seto.

Morton, L. and T. Phillips, 2012. Wound Healing Update. Semin. Cutan. Med. Surg., 31: 33-37. DOI: $10.1016 /$ j.sder.2011.11.007

Pawitan, J. and I. Liem, 2013. Simple lipoaspirate washing using a coffee filter. Asian Biomed., 7: 333-338. DOI: 10.5372/1905-7415.0703.184

Pawitan, J. and M. Leviana, 2017. Prospect of umbilical cord mesenchymal stem cell culture waste in regenerative medicine. J. Global Pharma Technol., 9: $1-5$.

Rowan, M.P., L.C. Cancio, E.A. Elster, D.M. Burmeister and L.F. Rose et al., 2015. Burn wound healing and treatment: Review and advancements. Critical Care, 19: 243. DOI: 10.1186/s13054-015-0961-2

Sari, P., D.P. Septiara, H. Junaidi and L. Yunaini et al., 2018. Effect of human adipose-derived stem cell in collagen gel on relative expression level of vascular endothelial growth factor-A of deep dermal burn healing. Asian J. Pharmaceutical Clinical Res., 11: 383. DOI: 10.22159/ajpcr.2018.v11i7.24161

Wei, X., X. Yang, Z.P. Han, F.F. Qu and L. Shao et al., 2013. Mesenchymal stem cells: A new trend for cell therapy. Acta. Pharmacol. Sin., 34: 747-754. DOI: 10.1038/aps.2013.50

Yang, Z., 2015. Chinese Burn Surgery. 1st Edn., Springer, ISBN-10: 9401785759, pp: 481. 